\title{
THE EFFECT OF TECHNOLOGY AND ADMINISTRATIVE AUTOMATION ON EMPLOYEES' WORK LIFE QUALITY (CASE STUDY: DEPARTMENT OF YOUTH AND SPORTS OF KERMANSHAH PROVINCE)
}

\author{
Zahra Keshtmand \\ MA Sport Management, Kurdistan Science and Research Branch, Islamic Azad University, Sanandaj, \\ Iran \\ Mohammad Nowrozian \\ MA Student Sport Management, Sanandaj Branch, Islamic Azad University, Sanandaj, Iran \\ Khidan Hatami \\ Department of Physical Education and Sport Science, Sanandaj Branch, Islamic Azad University, \\ Sanandaj, Iran
}

\begin{abstract}
The aim of this study was to evaluate the Effect of technology and administrative automation on Employees' work life quality of Directorate General of Youth and Sports Kermanshah province. This research is descriptive-correlation method that has been conducted as a field study. The statistic population was the General Directorate of Youth and Sports in Kermanshah province which their number was 125. Morgan table was used to determine sample sizes of 95 patients were randomly selected to participate. To collect data, a questionnaire Adel automation (2008), and the quality of working life and Walton (1973) were used. Validity was confirmed by experts. Reliability of questionnaires were obtained $\alpha=0 / 92$ for administrative automation and $\alpha=0 / 76$ for quality of working life by Cronbach alpha. To analyze the data, the Kolmogorov-Smirnov test was used, Pearson was performed using SPSS version 22. The results showed that the use of technology and administrative automation has a significant positive effect on the quality of working life of employees in the General Directorate of Youth and Sports in Kermanshah province.
\end{abstract}

Keywords: technology, administrative automation, quality of working life, employees

\section{INTRODUCTION}

During recent years use and operation of office automation systems has been prevalent in our country and so many organizations are willing to utilizing and use of these systems and they are ready to spend huge amounts for the establishment and use of these systems. Office automation is mechanism that for the purpose of improving the efficiency the organization through applying effective management and applying the activities of the organization by using electronic circulation of organizational correspondence, easy searching of the stored information, Rapid and timely response to clients, Removing paper from office correspondence cycle, appropriate control over the users, Registration and maintenance of optimal information and improve communication within the organization. And it is responsible for creating internal communications and also people of the organization with outside of the organization. Automation information system can support employees to achieve their goals (Ranji,Jifroodi, 2008). Office automation includes all formal and informal electronic systems which relates to communicate information between peoples inside and outside of the organization (Rahimi kia, 2010) and is one of the factors that can play an important role of increasing productivity and performance (Jahanbakhsi, 2009). a research which has done by Mohseni indicated that all factors such as quick and easy access to data, Establishing uniformity in all matters, speed in doing works, accuracy and precision of operation have influenced on employee performance. As a result automation leads to increase Employee performance (Mohseni, 2006), Kay, 2004 states in a research under the title:" Study and design of automation systems" the University of California 
recently automation designing becomes more and more in order to optimization strategies and different administrative levels in cost saving, manpower and time. Automation facilitate doing service affairs and increases productivity. The automation process requires preparing and instructions and system activity diagrams. Automation system design is based on the behavior and performance of the system and different structural process performed according to that (Kay, 2004). Sheikh Baklo et al (2012) examined the effects of office automation on the efficiency in their research and results indicated that office automation has impacts on the efficient use of time response to the customers and accuracy in doing things and resulted to increasing efficiency. Sharifzadeh in his research with the title of Analysis of the relationship between the extent of automation and organizational effectiveness indicated that by increasing the extent of automation the efficiency will be increased. And the difference is significant between the two organizations with the same degree of automation. This means that in the organizations that have type automation degree is not observed a significant difference in terms of performance. Well as by increasing degree of automation extent, increases employee satisfaction. Sarafizadeh and Alipour (2009) in a research examined the effect of office automation on productivity of human resources and indicated that the implementation of office automation on factors such as efficiency, effectiveness and productivity in the field of human resources has a direct impact yet the extent of effectiveness has not been impressive. As well as the development of office automation is enough newly that there was no enough time for the study and basic research about the results and its effects and we can say that this issue has analyzed very little. About the usefulness of office automation of the companies and offices many discussions has been proposed but most experts that for proving that issue had pay attention to economic and management dimension. In this regard, one of the most important goals of the network health and life quality improvement of their employees is increasing efficacy. In recent decades, psychologists considered the psychometric properties of the employees in the organizations. As experts in organizational behavior and human resources have particular attention to the human characteristics to take actions for increasing efficiency by identifying the variables (Mirzapour, 2010). Therefore, work life quality is a new sense of job satisfaction that has been considered by managers (Armaghan, 2012). Quality of Work Life is a comprehensive program that is dedicated to promoting employee satisfaction (Boojmehrani et al, 2012). Karaen 1997 defines work life quality and the complex interaction system components work with tasks, invoices and organizational factors, environment, tools, and technology. Dehnavi (2013) as a result of work life quality on a hand analyses the effective factors on the growth and development of the organizational and from the other hand offers strategies to increase employee productivity and organization(Armaghan,2012).

According to what was mentioned, a good quality of life for employees in an organization affects the efficiency and $\mathrm{n}$ performance. Another factor that can play an important role in increasing productivity is information technology. Also, since the sports organizations such as Directorate of Sport and Youth is one of the organizations that its employees play a key role in it and the presence and importance of employees is more than before due to visiting athletes and the general public, and with regard to the use of information technology and its expansion to appear on sports organizations also need to automate the professional staff, and may also be increased. And since research and studies to the social and economic consequences of automation in the bright sports organizations, very little has been done. And statistics that accurately shows the usefulness of uselessness and psychological variables such as quality of life in the community and staff and staff has not been achieved. Therefore, this study aimed to investigate the effect of administrative automation and technology on the quality of work life in the General Directorate of Youth and Sports of Kermanshah Province.

\section{MATERIAL AND METHODS}

This research is descriptive-correlation method that has been conducted as a field study. The statistic population was the General Directorate of Youth and Sports in Kermanshah province which their number was 125. Morgan table was used to determine sample sizes of 95 patients were randomly selected to participate. To collect data, a questionnaire Adel automation (2008), and the quality of working life and Walton (1973) were used. Validity was confirmed by experts. Reliability of questionnaires were obtained $\alpha=0 / 92$ for administrative automation and $\alpha=0 / 76$ for quality of 
working life by Cronbach alpha. To analyze the data, the Kolmogorov-Smirnov test was used, Pearson was performed using SPSS version 22.

\section{RESULTS}

or the normal statistical distribution of data, i.e., whether data variables follow the normal statistical distribution or not, non-parametric Kolmogorov-Smirnov test is used to determine the nature of variable data. Parametric or non-parametric tests (tests free distribution) is used for the analysis. Kolmogorov-Smirnov test results to fit a normal distribution in Table 1, below. Assumptions for the Kolmogorov-Smirnov test are as follows.

Table 1: result of Kolmogorov-Smirnov test

\begin{tabular}{|c|c|c}
\hline variable & $\mathrm{Z}$ & $\mathrm{P}$ \\
\hline IT and Office automation & 1.353 & 0.058 \\
\hline Life Quality Work & 0.988 & 0.301 \\
\hline Reaching to goal & 0.961 & 0.359 \\
\hline Decision making quality & 0.878 & 0.399 \\
\hline Quality of analyzing data & 1.571 & 0.067 \\
\hline Entering new ideas & 1.421 & 0.058 \\
\hline Answering quality & 1.035 & 0.124 \\
\hline Modification of business processes & 0.919 & 0.310 \\
\hline
\end{tabular}

According to Table 1, the test results show that the distribution of the data obtained to normal. As a result, there is the possibility of using parametric tests. To evaluate the significance of these tests hypotheses, Pearson and regression are used. Normal and other variable data Pearson test is abnormal.

Pearson test result is shown in Table 2.

Table 2: result of Pearson test

\begin{tabular}{|c|c|c|c}
\hline independent variable & dependent variable & R & Sig. \\
\hline IT and Office automation & Life Quality Work & 760.0 & 000.0 \\
\hline IT and Office automation & Reaching to goal & 835.0 & 000.0 \\
\hline IT and Office automation & Decision making quality & 644.0 & 000.0 \\
\hline IT and Office automation & Quality of analyzing data & 697.0 & 000.0 \\
\hline IT and Office automation & Entering new ideas & 793.0 & 000.0 \\
\hline IT and Office automation & Answering quality & 313.0 & 008.0 \\
\hline IT and Office automation & $\begin{array}{c}\text { Modification of business } \\
\text { processes }\end{array}$ & 453.0 & 001.0 \\
\hline
\end{tabular}

The results showed that the use of technology and administrative automation has a significant positive effect on the quality of working life of employees in the General Directorate of Youth and Sports in Kermanshah province.

\section{DISCUSSION AND CONCLUSION}

Result show that there is a significant positive correlation between information technology and automation and all its dimensions and the quality of life in Youth and Sports in Kermanshah province. Above results is to some extent is in consist with findings of Hasanzade (2005), Mosavi and Norozi (2009), Rahimi kya et al (2010), Lovnete Pieto (2004). Sarrafzadeh and Alipur (2009) in a research examined the office automation application on the productivity of human resources and indicated that applying office automation had direct impact on the factors such as the efficiency, effectiveness and productivity in the human resources field but the amount of impact has not been impressive. Sharifzadeh in his research indicated that by increasing the extent of Automation staff satisfaction increases. Today automation causes that shape of doing things be the same and prevented the 
difference between the different tastes in doing things, interpretation of the Rules and Regulations. In other words consistency is obtained in doing affairs that causes to increase performance of employees. Office automation system is responsible for creating internal communications of the organizations and also the employees of the organization with peoples outside of the organization this connection helps improve coordination of activities and qualitatively of works that this in turn causes to increase satisfaction of people and thus improves the quality of life of persons. Quality of life as a goal provides improvement of organizational performance through creating more challenging jobs and working environments in all levels of organization. Therefore, according to the results of the efficiency and quality of automation and its dimensions such as reaching the goal, the quality of decision-making, the quality of data analysis, and entry of new ideas, accountability and reform business processes run better health and higher sport organization causes to increasing quality of staff's life. Thus considering this fact is necessary for authorities and sport managers. An organization that their employees that are in desirable and good state in terms of work life quality and considering internal and external demands and its office automation is high and working group members, trusted group, coordination, and cooperation be necessary consequently increases quality of work life the employees of the organization. We can say that Youth and Sports in Kermanshah province due to using computer and electronically tools have more independence for their employees. And this independence of working increases their satisfaction. While the variety of work increases since technologic tools decreases a lot of unnecessary and repetitive tasks of people. Therefore, due to the influence and role of automation on the quality of work life of employees open fields and infrastructures is provided in the Youth and Sports in Kermanshah province so that the medical system increasingly placed in the path of growth and development. And by using the specialized and dominant staffs of automation and information technology provide the applying fields for it in the work condition and creating motivation in the staffs so that causes to increase job satisfaction and consequently improvement the life quality of employees.

\section{REFERENCES}

Armagan, J. (2012). Work-life quality and efficacy of staff in the Department of Physical Education in Western Azerbaijan province, a Master's thesis, Islamic Azad University of Boroujerd.

Boozhmehrany, S et al. (2012). Assessing the Quality of Working Life and Levels of Depression in Athletes and Non-Athlete Staff in National Olympic and Paralympics Academy of Iran $\mathrm{m}$ International Journal of Academic Research in Business and Social Sciences, October 2012, Vol. 2, No. 10

Dehnavi, A , et al. (2013). Perceptions of coaching behavior and quality of work life in athletes competing in Iran track and field league 2012-13. European Journal of Experimental Biology, 2013, $3(2): 6-12$

Hassanzadeh, M. (2005). Comparison Bhutan performance before and after the implementation of automation projects, Masters Public Administration. Higher Institute of Education Management and Planning.

Kai. (2004). study and design of automation systems, university of California.

Mirzapour, A.A. (2010). The relationship between motivation and commitment of volunteers in the tenth Sport Cultural Olympiad students across in Iran, Sport Management master's thesis, University of Mazandaran.

Rahimi Kia, Amin et al. (2010). investigated the use of automation in Khorramabad municipal employee productivity, urban management, 27, 99-124

Ranji jifrodi, Nima. (2008). study on improvement of management decisions office of Vice-Governor and, Guilan a Commercial Management, Azad University of Rasht.

Sarrafzadeh, A and Alipur, S. (2009). A survey effect of office automation on human resources productivity. Journal of Management Development and Transformation 3, 17-24.

Sharif Zadeh, F. (2010). Analyzes the relationship between the extent of automation and organizational effectiveness, Journal of Management Studies Information Technology 1(2), 37-907.

Sheikh Baklo, S. et al. (2012). Examines the impact of automation on performance. Journal of Management, 9, 53-58. 